\title{
Pengaruh Penerapan Sistem Reward terhadap Kinerja Auditor Badan Pemeriksa Keuangan RI Perwakilan Provinsi Sulawesi Tenggara
}

\author{
Nurul Arsy Utami ${ }^{1}$; Muh. Nasir ${ }^{2}$; Sartono $^{3}$ \\ 1,2,3 Universitas Halu Oleo, nurularsyutami@gmail.com
}

\begin{abstract}
Abstrak
Tujuan penelitian ini adalah untuk mengetahui bagaimana pengaruh penerapan sistem reward berpengaruh secara positif dan signifikan terhadap kinerja auditor pada Badan Pemeriksa Keuangan RI Perwakilan Provinsi Sulawesi Tenggara. Teknik analisis data penelitian ini menggunakan analisis kuantitatif berupa uji hipotesis dengan menggunakan regresi sederhana yang didasarkan pada data dari 18 responden yang telah melengkapi seluruh pertanyaan dalam kuesioner. Penelitian ini dilakukan di Badan Pemeriksa Keuangan RI Perwakilan Provinsi Sulawesi Tenggara. Instrumen penelitian menggunakan lembar kuesioner. Jenis data terdiri dari data primer dan data sekunder. Hasil penelitian ini menunjukkan bahwa penerapan sistem reward berpengaruh secara positif dan signifikan terhadap kinerja auditor di Badan Pemeriksa Keuangan RI Perwakilan Provinsi Sulawesi Tenggara.
\end{abstract}

Kata kunci : auditor, reward sistem, kinerja,

\begin{abstract}
The purpose of this research is to determine whether the implementation of the reward system had a positive and significant effect on the auditor's performance at The Audit Board of The Republic Indonesia, Representative of Southeast Sulawesi Province. The technique that is use to analyze data of this research is quantitative analysis with hypothesis testing using simple regression based on data from 18 respondents who has complete all the questions in the questionnaire. This research conducted at The Audit Board of The Republic Indonesia, Representative of Southeast Sulawesi Province. This research instrument was questionnaire. The type of data consist of primary and secondary data. This research result indicate that the implementation of the reward system has a positive and significant effect on the auditor's performance at The Audit Board of The Republic Indonesia, Representative of Southeast Sulawesi Province.
\end{abstract}

Keywords : auditor, performance, reward, system

\section{Pendahuluan}

Tata kelola pemerintahan yang baik atau good governance sebagaimana didefinisikan oleh United Nations Development Programme (UNDP) dalam Adisasmita (2010) adalah penerapan kekuasaan ekonomi, politik dan administratif untuk mengelola urusan suatu bangsa pada semua tingkat. Good governance bertujuan agar tercipta pemerintahan yang baik dan bersih, meliputi aspek profesionalitas, akuntabilitas, transparansi, pelayanan prima, demokrasi dan partisipasi, efisiensi dan efektivitas, supremasi hukum, dan bervisi strategis. 
Menurut Mardiasmo (2005) terdapat tiga aspek utama yang mendukung tata kelola pemerintahan yang baik atau good governance yaitu pengawasan, pengendalian dan pemeriksaan. Ketiga aspek tersebut mencakup semua unsur pokok dalam penyelenggaraan pemerintahan, termasuk didalamnya pemeriksaan keuangan negara. Oleh karena itu, diperlukan lembaga yang bekerja secara independen dan profesional dalam menjalankan tugas pemeriksaan. Lembaga tersebut adalah Badan Pemeriksa Keuangan Republik Indonesia atau BPK RI.

Badan Pemeriksa Keuangan Republik Indonesia sebagaimana disebutkan dalam Undang-Undang Nomor 15 Tahun 2006 tentang Badan Pemeriksa Keuangan, adalah lembaga negara yang bertugas untuk memeriksa pengelolaan dan tanggungjawab keuangan negara. Pemeriksa adalah orang yang melakukan tugas pemeriksaan pengelolaan dan tanggungjawab keuangan negara untuk dan atas nama BPK. BPK berwenang menilai dan/atau menetapkan jumlah kerugian negara yang diakibatkan oleh perbuatan melawan hukum baik disengaja maupun lalai yang dilakukan oleh bendahara, pengelola keuangan negara, serta lembaga atau badan yang menyelenggarakan pengelolaan keuangan negara.

Auditor BPK dalam menjalankan tugasnya berpedoman pada Standar Pemeriksaan Keuangan Negara atau SPKN. Kualitas hasil kerja auditor dapat juga diartikan sebagai kinerja auditor. Kinerja merupakan hasil kerja seseorang atau sekelompok dalam sebuah organisasi sesuai dengan tanggungjawab dan wewenang yang telah diberikan. Terdapat dua faktor yang mempengaruhi kinerja yaitu faktor internal dan faktor eksternal. Faktor internal berhubungan dengan sifat-sifat seseorang yang meliputi sikap, kepribadian, sifat fisik, keinginan atau motivasi (reward dan punishment), umur, jenis kelamin, pendidikan, pengalaman kerja, latar belakang budaya dan variabel-variabel personal lainnya. Sedangkan faktor eksternal berhubungan dengan lingkungan, kepemimpinan, tindakan-tindakan rekan kerja, jenis latihan dan pengawasan, sistem upah dan lingkungan sosial (Timpe, 1992 dalam (Riyadi, 2011).

BPK RI Perwakilan Provinsi Sulawesi Tenggara sebagai perwakilan BPK di daerah menerima penghargaan WBK (Wilayah Bebas Korupsi) pada Desember 2018 dari Kementrian Pendayagunaan Aparatur Negara dan Reformasi Birokrasi. 
Dengan diperolehnya Penghargaan sebagai Unit Kerja Pelayanan berpredikat Wilayah Bebas dari Korupsi (WBK), BPK Perwakilan Provinsi Sulawesi Tenggara telah membuktikan mampu menjalankan menjalankan pembangunan Zona Integritas dengan melakukan peningkatan Ketatalaksanaan, SDM Aparatur, Pengawasan, Akuntabilitas, Pelayanan Publik dan Budaya Kerja Aparatur.

Sebagai bagian dari faktor eksternal pemberian reward merupakan unsur penting dalam penciptaan tinggi atau rendahnya kinerja auditor. Untuk tetap menjaga kinerja yang telah dicapai, pemberian motivasi berupa penghargaan atau reward merupakan metode yang tepat. Dalam hal ini, perbedaan kinerja antara satu auditor dengan auditor yang lain dalam satu lingkungan kerja yang sama akan menghasilkan produktivitas kerja yang berbeda.

\section{Metode}

Jenis penelitian ini adalah penelitian kuantitatif yaitu penelitian yang menekankan pada data-data numerikal (angka) yang diolah menggunakan statistika.Penelitian ini akan dilaksanakan di Badan Pemeriksa Keuangan Republik Indonesia Perwakilan Provinsi Sulawesi Tenggara yang terletak di Jalan Sao-Sao No. 10 Kendari. Dengan pertimbangan bahwa Badan Pemeriksa Keuangan merupakan lembaga negara yang memiliki tingkat kepercayaan tinggi serta bekerja secara independen dan professional dalam melakukan tugas pemeriksaan. Populasi dalam penelitian ini adalah auditor Badan Pemeriksa Keuangan RI Perwakilan Provinsi Sulawesi Tenggara yang terdiri dari sub auditorat sultra I dan sub auditorat sultra II dengan jumlah 33 auditor. Teknik penarikan sampel dalam penelitian ini adalah insendental sampling yaitu metode pengambilan sampel berdasarkan siapa saja yang ada pada lokasi penelitian dan dipandang sesuai dengan kriteria sumber data penelitian. Dalam hal ini, auditor BPK Perwakilan Provinsi Sulawesi Tenggara yang berada ditempat sebanyak 18 orang dan telah memenuhi kriteria sebagai responden dalam penelitian ini. 


\section{Hasil dan Pembahasan}

\section{Statistik Deskriptif Kategorikal Responden}

Dalam penelitian ini terdapat 18 orang auditor yang menjadi responden penelitian dan responden penelitian tersebut diklasifikasikan dalam jenis kelamin, usia, pendidikan terakhir, pendidikan, lama bekerja, jabatan dan peran. Dari keseluruhan responden terdapat 9 orang laki-laki (50\%) dan 9 orang (50\%) perempuan. Diketahui pula bahwa auditor dengan usia 20-30 tahun sebanyak 2 orang (11\%), usia 31-40 tahun sebanyak 8 orang (44\%) dan yang berusia $>40$ tahun sebanyak 2 orang (11\%). Dari segi pendidikan terakhir, sebanyak 13 orang (72\%) responden berpendidikan $\mathrm{S} 1,4$ orang berpendidikan $\mathrm{S} 2(22 \%)$ dan tidak ada responden yang berpendidikan $\mathrm{S} 3$.

Berdasarkan pendidikan diketahui bahwa responden dengan pendidikan akuntansi sebanyak 10 orang (56\%), pendidikan hukum sebanyak 2 orang (11\%), manajemen 1 orang (6\%), pendidikan teknik 4 orang (22\%) dan responden dengan pendidikan lainnya 1 orang (6\%). Dilihat dari lama bekerja, sebanyak 4 orang (22\%) responden bekerja dalam rentang waktu 0-5 tahun, 7 orang responden (39\%) bekerja dalam rentang waktu 5-10 tahun dan 7 orang (39\%) bekerja dalam rentang waktu $>10$ tahun.

Sementara untuk karakteristik jabatan diketahui bahwa sebanyak 6 orang (33\%) pemeriksa pertama, pemeriksa muda sebanyak 11 orang $(61 \%)$ dan tidak ada responden dengan jabatan pemeriksa madya. Sedangkan untuk karakteristik peran, sebanyak 12 orang (67\%) merupakan anggota tim, 5 orang (29\%) merupakan ketua tim dan tidak ada responden yang berperan sebagai pengendali teknis. Selain itu, terdapat responden yang tidak mengisi data identitas responden dengan lengkap sehingga karakteristiknya tidak diketahui pasti. Masing-masing karakteristik tersebut sebanyak jenis kelamin 1 orang (6\%), usia 6 orang (33\%), pendidikan terkahir 1 orang (6\%), jabatan 1 orang $(6 \%)$ dan peran 1 orang $(6 \%)$.

\section{Statistik Deskriptif Variabel Penelitian}

Analisis deskripsi untuk setiap variabel penelitian berdasarkan pada respon atau jawaban responden dari setiap pernyataan dengan skala sangat tidak 
setuju, tidak setuju, kurang setuju, setuju dan sangat setuju. Deskripsi jawaban akan dijelaskan berdasarkan frekuensi hasil perhitungan mean masing-masing variabel. Interval kelas ditentukan sebagai berikut :

Interval Kelas $=\frac{\text { Nilai terbesar }- \text { Nilai terkecil }}{\text { Jumlah Kelas }}$

Interval Kelas $=\frac{5-1}{5}=0.8$

Nilai batasan masing-masing kelas diperoleh dari interval kelas yaitu berjarak 0.8 sesuai hasil perhitungan. Kemudian, nilai rata-rata tiap variabel dinilai berdasarkan kategori interval kelas. Kategori nilai interval adalah sebagai berikut :

Tabel 1. Pengkategorian Interval Kelas

\begin{tabular}{|l|l|l|l|}
\hline No. & Interval & Kategori & Keterangan \\
\hline 1. & $1.00-1.08$ & 1 & Sangat Rendah \\
\hline 2. & $1.09-2.06$ & 2 & Rendah \\
\hline 3. & $2.07-3.40$ & 3 & Cukup \\
\hline 4. & $3.41-4.20$ & 4 & Tinggi \\
\hline 5. & $4.21-5.00$ & 5 & Sangat Tinggi \\
\hline
\end{tabular}

Sumber : data primer, diolah sendiri (2019)

\section{Variabel Sistem Reward}

Variabel sistem reward dalam penelitian terdiri dari 24 butir pernyataan dimana pernyataan sangat setuju menggambarkan bahwa sistem reward sangat berpengaruh dalam meningkatkan kinerja auditor oleh BPK RI Perwakilan Provinsi Sulawesi Tenggara. Pilihan jawaban masing-masing pernyataan sangat setuju (SS) bernilai 5, setuju (S) bernilai 4, kurang setuju (KS) bernilai 3, tidak setuju (TS) bernilai 2 dan sangat tidak setuju (STS) bernilai 1 .

Berdasarkan distribusi frekuensi dalam tabel dapat diketahui bahwa secara keseluruhan nilai rata-rata variabel sistem reward (X) adalah 3.76 dengan kategori tinggi. Hal ini menunjukkan bahwa sistem reward yang berlaku di BPK Provinsi Sulawesi Tenggara memiliki tingkat pengaruh yang tinggi terhadap kinerja auditor. 


\section{Variabel Kinerja Auditor}

Variabel kinerja dalam penelitian ini terdiri dari 14 butir pernyataan, dimana pilihan sangat setuju menggambarkan kinerja auditor BPK RI Perwakilan Provinsi Sulawesi Tenggara tinggi. Pilihan jawaban pernyataan sangat setuju (SS) diberi nilai 5, setuju (S) diberi nilai 4, kurang setuju (KS) diberi nilai 3, tidak setuju (TS) diberi nilai 2 dan sangat tidak setuju (STS) diberi nilai 1.

Distribusi frekuensi dalam tabel menunjukkan bahwa nilai rata-rata variabel kinerja auditor adalah 3.39 dengan kategori cukup. Hal ini menunjukkan bahwa auditor BPK Perwakilan Provinsi Sulawesi Tenggara memiliki kinerja yang cukup.

\section{Uji Instrumen Penelitian}

\section{a. Uji Validitas}

Uji validitas digunakan untuk mengukur sah/valid atau tidaknya suatu kuesioner. Kuesioner dikatakan valid jika pertanyaan pada kuesioner mampu untuk mengungkapkan sesuatu yang akan diukur oleh kuesioner tersebut (Suntoyo, 2009 : 72). Pengujian dilakukan dengan membandingkan nilai $r$ hitung dengan $r$ tabel untuk degree of freedom $=\mathrm{n}-\mathrm{k}$. Jika $\mathrm{r}$ hitung untuk tiap butir pernyataan positif dan lebih besar dari $r$ tabel maka butir pernyataan adalah valid.

Dari hasil pengujian diatas, dapat disimpulkan bahwa seluruh item pernyataan adalah valid dengan diperolehnya $r_{h i t u n g}>r_{\text {tabel }}$ pada seluruh variabel penelitian.

\section{b. Uji Reliabilitas}

Uji reliabilitas adalah pengujian untuk mengukur suatu kuesioner yang merupakan indikator dari variabel atau konstruk. Butir pertanyaan dikatakan reliabel atau andal apabila jawaban responden terhadap pertanyaan adalah konsisten. Dalam hal ini pengukuran dilakukan dengan mengukur korelasi antar skor jawaban pada butir pertanyaan yang sama dengan cronbach alpha. Konstruk atau variabel dikatakan reliabel jika memberikan nilai cronbach alpa $>0.60$. Dari hasil pengujian diatas dapat disimpulkan bahwa seluruh pernyataan untuk setiap variabel adalah reliabel atau handal, dimana keseluruhan nilai cronbach alpha memiliki nilai $>0.60$. 


\section{c. Uji Regresi Sederhana}

Uji regresi sederhana digunakan untuk mengetahui pengaruh variabel bebas terhadap variabel terikat. Uji ini untuk mengetahui ada tidaknya pengaruh sistem reward terhadap kinerja auditor BPK. Berdasarkan hasil analis dalam Tabel Coefficients (a) didapatkan nilai $\beta_{0}$ sebesar 29.211 dan nilai koefisien variabel X $\left(\beta_{1}\right)$ sebesar 0.849 . Jadi, persamaan regresinya adalah sebagai berikut :

$\mathrm{Y}=\mathrm{a}+\mathrm{bX}=29.211+0.849 \mathrm{X}$

Konstanta sebesar 29.211 menyatakan bahwa jika terdapat kenaikan skor sistem reward (X), maka skor kinerja auditor (Y) adalah sebesar 29.211. Koefisien regresi sebesar 0.849 pada variabel $\mathrm{X}$ menyatakan bahwa setiap penambahan satu skor sistem reward $(\mathrm{X})$ akan memberikan nilai sebesar 0.849 pada skor kinerja auditor (Y).

\section{Hasil Uji Hipotesis}

Hipotesis pertama yang diajukan menyatakan ada pengaruh penerapan sistem reward (X) terhadap kinerja auditor (Y) BPK RI Perwakilan Provinsi Sulawesi Tenggara. Formula yang digunakan untuk menghitung seberapa besar pengaruh penerapan sistem reward terhadap kinerja auditor adalah rumus uji $t$.

Hasil analisis uji $t$ dengan program IBM SPSS Statistic 25 memperoleh nilai signifikan $0.001<0,05$. Sehingga $\mathrm{H}_{0}$ ditolak dan $\mathrm{H}_{\mathrm{a}}$ tak ditolak. Hal ini berarti bahwa hipotesis yang menyatakan ada pengaruh antara penerapan sistem reward dan kinerja auditor tak ditolak. Sehingga dapat disimpulkan bahwa terdapat pengaruh yang positif dan signifikan antara penerapan sistem reward $(\mathrm{X})$ dan kinerja auditor (Y).

\section{Pembahasan Hasil Penelitian}

Penelitian ini bertujuan menguji pengaruh penerapan sistem reward terhadap kinerja auditor pada Badan Pemeriksa Keuangan RI Perwakilan Provinsi Sulawesi Tenggara. Berdasarkan uji hipotesis yang telah dilakukan, diperoleh bahwa variabel sistem reward berpengaruh secara positif dan signifikan terhadap kinerja auditor. Hasil pengujian statistik dengan analisis uji $t$ menunjukkan nilai $p$ value 0.001 dengan tingkat signifikansi 0.05 . Perbandingan $0.001<0.05$ 
menunjukkan bahwa $\mathrm{H}_{0}$ ditolak dan $\mathrm{H}_{\mathrm{a}}$ diterima. $\mathrm{H}_{0}$ atau hipotesis nol yang menyatakan tidak ada pengaruh penerapan sistem reward terhadap kinerja auditor BPK RI Perwakilan Provinsi Sulawesi Tenggara ditolak. Dan $\mathrm{H}_{\mathrm{a}}$ atau hipotesis alternatif yang menyatakan ada pengaruh penerapan sistem reward terhadap kinerja auditor BPK RI Perwakilan Provinsi Sulawesi Tenggara diterima.

Hasil pengujian hipotesis ini sejalan dengan pendapat Robbins yang menyatakan penerapan sistem reward akan menjadi motivasi atau dorongan sendiri bagi pegawai untuk mencapai kinerja yang tinggi serta prestasi kerja dalam rangka mencapai tujuan organisasi.

\section{Kesimpulan}

Berdasarkan hasil penelitian dan pembahasan yang telah diuraikan, hipotesis pertama yang menyatakan ada pengaruh penerapan sistem reward terhadap kinerja auditor BPK RI Perwakilan Provinsi Sulawesi Tenggara diterima. Dengan kata lain, hipotesis kedua yang menyatakan tidak ada pengaruh penerapan sistem reward terhadap kinerja auditor BPK RI Perwakilan Provinsi Sulawesi Tenggara ditolak.

Pengujian pada hipotesis pertama menunjukkan hasil analisis uji $t$ memperoleh nilai signifikansi $0.001<0.05$. Sehingga dapat disimpulkan bahwa $\mathrm{H}_{0}$ ditolak dan $\mathrm{H}_{\mathrm{a}}$ tak ditolak yang berarti bahwa ada pengaruh penerapan sistem reward (X) terhadap kinerja auditor BPK RI Perwakilan Provinsi Sulawesi Tenggara (Y). Pengaruh variabel $\mathrm{X}$ terhadap variabel $\mathrm{Y}$ yaitu positif dengan total pengaruh sebesar $88.8 \%$. Hal tersebut bermakna bahwa sistem reward berpengaruh siginifikan terhadap kinerja, dimana semakin baik sistem reward yang diterapkan maka semakin baik kinerja auditor BPK RI Perwakilan Provinsi Sulawesi Tenggara.

\section{Referensi}

Abdullah, M. (2014). Manajemen Dan Evaluasi Kinerja Karyawan. Yogyakarta: Aswaja Pressindo. 
Adisasmita, R. (2010). Manajemen Pemerintah Daerah. Yogyakarta : Graha Ilmu. BPK RI. (2018). BPK Perwakilan Provinsi Sulawesi Tenggara Terima Penghargaan WBK (kendari.bpk.go.id diakses 10 Januari 2019, 20:10 WITA)

BPK RI Perwakilan Provinsi Sulawesi Tenggara. 2018. (kendari.bpk.go.id diakses 16 Januari 2019, 22:00 WITA)

Fadel, Muhammad. (2009). Reinventing Local Government. Jakarta: Elex Media Komputindo.

Fembriani, A dan Budiartha, I.K. (2016). Faktor-Faktor Yang Memengaruhi Kinerja Auditor BPK RI Perwakilan Provinsi Bali. Jurnal Ekonomi dan Bisnis. ISSN:2337-3067.

Gunawan, Imam. (2016). Pengantar Statistika Inferensial. Depok: PT Rajagrafindo Persada

Ikhsanudin, Arief. (2018). Survei LSI-ICW: KPK dan Presiden Lembaga Paling Dipercaya (https://news.detik.com/berita/4337909/survei-lsi-icw-kpkdan-presiden-lembaga-paling-dipercaya diakses 9 Januari 2019, 20:00 WITA)

Mahmudi. (2005). Manajemen Kinerja Sektor Publik. Yogyakarta : UPP AMP YPKN.

Mardiasmo. (2005). Akuntansi Sektor Publik Edisi 2. Yogyakarta : Andi.

Peraturan Badan Pemeriksa Keuangan Republik Indonesia Nomor 1 Tahun 2017 tentang Standar Pemeriksaan Keuangan Negara.

Sugiyono. (2013). Statistika Untuk Penelitian. Bandung : Alfabeta.

Suntoyo, Danang. (2009). Analisis Regresi dan Uji Hipotesis. Yogyakarta: Media Pressindo.

TAP MPR No.VI/MPR/2002 tentang Rekomendasi Atas Laporan Pelaksanaan Putusan Majelis Permusyawaratan Rakyat Republik Indonesia Oleh Presiden, DPA, DPR, BPK, MA

Undang-Undang Nomor 15 Tahun 2006 tentang Badan Pemeriksa Keuangan 